\title{
Teúrgia: camino de Jámblico a lo inefable
}

\author{
JosÉ Molina AYAlA \\ Centro de Estudios Clásicos \\ Instituto de Investigaciones Filológicas \\ Universidad Nacional Autónoma de México \\ josemolina@correo.unam.mx
}

\begin{abstract}
Resumen: Jámblico de Calcis postuló, por razones metafísicas, la teúrgia como vía única para alcanzar la unión con el principio supremo de todo lo que existe. Estableció este principio como una realidad totalmente trascendente, no alcanzable mediante la razón, hizo de la materia instrumento para el ascenso del alma hacia dicho principio. Al mismo tiempo propuso explícitamente una mística de "comunión" con el cosmos y con las otras almas, a diferencia de Plotino, quien postulaba el abandono de todas las cosas y concebía la unión con el Uno como una huida de un solo hacia el Solo.
\end{abstract}

Palabras clave: neoplatonismo, misticismo, inefable, divinización

\begin{abstract}
Iamblichus of Chalcis postulated theurgy on metaphysical grounds as the only way of communion with the supreme principle of everything that exists. Iamblichus set out this principle as a completely trascendent reality, ungraspable by reason, conceived matter as an instrument for the soul's ascent to that principle. Iamblichus proposed explicitly a mystic of communion with the cosmos and with the other souls, unlike Plotinus, who postulated the absolute withdrawal from everything and conceived the union with the One as an escape in solitude to the Solitary.
\end{abstract}

Key words: neoplatonism, mysticism, ineffable, deification

En el presente artículo intentaré exponer, desde una perspectiva ya libre de prejuicios y actualizada, una oposición —acaso aparente, pero motivada por diferentes concepciones metafísicas- entre la vía elegida por Plotino para ascender al Uno y la de Jámblico: a diferencia de Plotino, que postulaba el abandono de todas las cosas y concebía la unión con el Uno como una huida de un solo al Solo, Jámblico, al optar por la teúrgia como camino de ascenso hacia lo absolutamente trascendente, propone explícitamente una mística que podría denominarse de "comunión", no sólo con el cosmos, sino también con las otras almas. Si al hablar de Jámblico parezco imitar a Sócrates, que hablaba siempre las mismas cosas, incluso acerca de los mismos asuntos, ${ }^{1}$ válgaseme como disculpa

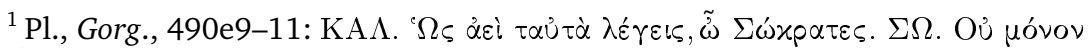
$\gamma \varepsilon, \tilde{\omega} \mathrm{\omega} \alpha \lambda \lambda \hat{\imath} x \lambda \varepsilon เ \varsigma, \dot{\alpha} \lambda \lambda \dot{\alpha} x \alpha \grave{i} \pi \varepsilon \rho \grave{i} \tau \tilde{\omega} \nu \alpha u \tau \tilde{\omega} \nu$.
}

Diánoia, volumen LV, número 65 (Noviembre 2010): pp. 125-149. 
la sentencia platónica de acuerdo con la cual es bueno decir y analizar dos o tres veces lo que es bello. ${ }^{2}$

En La ciudad de Dios, San Agustín afirma: "los filósofos famosísimos más recientes, a quienes pareció bien que Platón debía de ser seguido, no quisieron llamarse peripatéticos o académicos, sino platónicos. Entre éstos, por su gran fama, se encuentran los griegos Plotino, Jámblico, Porfirio." ${ }^{3}$ Estas líneas ponen de manifiesto el prestigio que rodeaba a esos filósofos, aun cuando ya hacía tiempo que habían muerto. ${ }^{4}$ Dado que se llamaban "platónicos", resalta el hecho de que se concebían a sí mismos como un renacimiento de doctrinas, según ellos, legítimas de Platón o incluso más antiguas, ${ }^{5}$ y no hay en la expresión agustiniana nada que sugiera que ese movimiento filosófico deba tenerse como el canto del cisne de la filosofía griega; por el contrario, se percibe renovada vitalidad. Hay que notar el orden en que San Agustín los menciona, un tanto sorprendente, porque pone a Jámblico detrás de Plotino, aunque Porfirio haya sido discípulo de Plotino y supuesto maestro de Jámblico. Tanto si el orden es ascendente o descendente en la intención del obispo, Jámblico ocupa un lugar destacado, y, a juzgar por las noticias de la época, Jámblico, saludado usualmente como el "divino" o con otros títulos no menos elogiosos, fue, en esa tradición filosófica, de mayor importancia que Plotino, aunque esto parece inusitado, ya que Plotino tiene mayor reconocimiento en la tradición occidental. Tratándose de Jámblico, nos enfrentamos, según San Agustín, a una figura de gran importancia dentro del platonismo inaugurado por Plotino. ${ }^{6}$

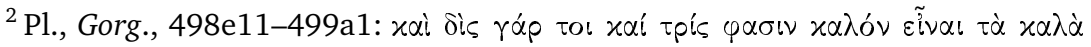

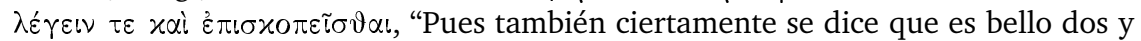
tres veces decir y analizar las cosas bellas". Véase también id., Philb., 60a: $\varepsilon_{\tilde{U}}^{\tilde{u}} \delta^{\circ} \dot{\eta}$

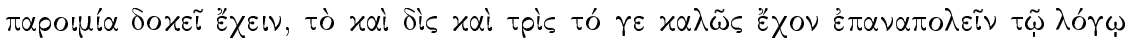
$\delta \varepsilon \tilde{\imath} \nu$ : "el proverbio parece ser correcto: es preciso repetir con la razón dos y tres veces lo que es bello".

${ }^{3}$ Aug., C.D., VIII, 12: "recentiores tamen philosophi nobilissimi, quibus Plato sectandus placuit, noluerint se dici Peripateticos aut Academicos, sed Platonicos. Ex quibus sunt valde nobilitati Graeci Plotinus, Iamblichus, Porphyrius."

${ }^{4}$ San Agustín terminó La ciudad de Dios hacia el año 426 (todas las fechas son después de Cristo). Plotino nació en Licópolis, Egipto, hacia el 204, y murió en Roma hacia el 270. Porfirio nació en Tiro hacia el 232 y murió hacia el 305. Jámblico nació en Calcis de Celesiria hacia el 242 y murió en Apamea, Siria, hacia el 326.

${ }^{5}$ Plot. V, 1, 8-9. Según Jámblico (Myst., I, 1-2), la filosofía griega tiene sus fuentes en el antiguo Egipto.

${ }^{6}$ La obra de Nasemann (1991) ha regresado definitivamente a Jámblico a la línea filosófica inaugurada por Plotino, poniendo de relieve incluso los vínculos lin-

Diánoia, vol. LV, no. 65 (Noviembre 2010). 
Ahora bien, uno de los rasgos característicos de este renacimiento platónico es la lectura que hace del diálogo Parménides: en esa lectura, el filósofo de Elea se ve obligado a dar un ejemplo de su método dialéctico; para ello, tiene que exponer las consecuencias alternativas para el Uno y para la multitud, suponiendo que el Uno es y que no es. El diálogo se desarrolla mediante un grupo de hipótesis que, según Porfirio y Jámblico, son nueve, de las cuales las tres primeras fueron interpretadas por Plotino en clave ontológica; es decir, según Plotino, las primeras hipótesis del diálogo se refieren a los principios más altos de todo cuanto existe. La primera hipótesis se refiere al Uno; la segunda, al Intelecto, y la tercera, al Alma del mundo. ${ }^{7}$

Leer a Platón e interpretarlo a la manera de Plotino fue derrotero de la filosofía subsiguiente; con la ascesis plotiniana parecía que la asi-

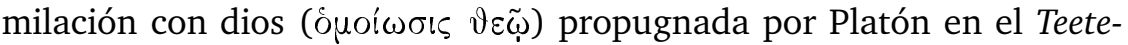
to, ${ }^{8}$ había encontrado un método. Para unirse al Uno, había que entrar en un proceso de conversión y elevación del alma: tomar conciencia sobre la propia dignidad y liberarse del mundo material; el alma debía recordar su propio linaje y tener presente la vileza de las cosas a las cuales está apegada y a las cuales considera, dada su enajenación, como algo honorable. ${ }^{9}$ Una manera sumaria de enunciar el objetivo del alma es "abandona todo" ( $\left.\alpha \alpha_{\varphi} \varepsilon \lambda \varepsilon \pi \alpha \dot{\nu} \tau \alpha\right)$; Plotino lo expresa así literalmente:

éste es el verdadero fin del alma: tocar aquella luz y, con la misma, contemplarla; no con luz de otro, sino contemplar la misma luz por la cual también ve. En efecto, es preciso que el alma contemple esta luz a través de la cual fue iluminada; pues ni siquiera ve al sol a través de la luz de otro. ¿Cómo, entonces, podría darse esto? Abandona todo. ${ }^{10}$

Visto de otra manera, pero equivalente, desde el punto de vista del sujeto que asciende, desde el alma, el camino de ascenso hacia el Uno debía hacerse de tal forma que, desprendida de todo, conseguida la güísticos entre ambos pensadores y señalando las innovaciones de parte de Jámblico. Por otra parte, Shaw (1995) ha ubicado correctamente las doctrinas de Jámblico sobre la teúrgia como desarrollos auténticamente platónicos.

${ }^{7}$ Plot., V, 1.

${ }^{8} \mathrm{Pl}$., Tht., $176 \mathrm{~b} 1$.

${ }^{9}$ Plot. V, 1, 1. Véase también I, 3, 1.

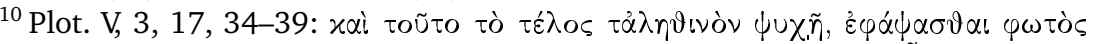

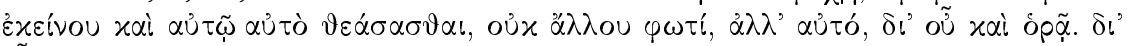

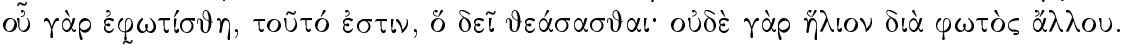

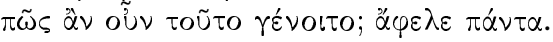

Diánoia, vol. LV, no. 65 (Noviembre 2010). 
soledad, el alma llegara a la presencia del Uno, que también está solo; era, precisamente en la expresión plotínica, una "fuga de un solo hacia

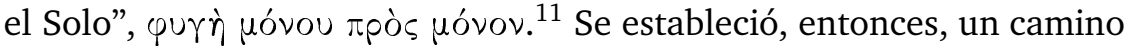
ascendente de purificación y de búsqueda de las virtudes: primero las naturales, después las éticas, posteriormente las políticas y las catárticas, y finalmente, las teoréticas o contemplativas. Pero el objetivo final de ese ascenso cada vez más solitario no era llanamente la pureza y la virtud por sí mismas, sino que el objetivo, hay que recordarlo, radicaba en la propia "deificación". Aunque uno se esfuerce por ser puro y virtuoso, "sin embargo", dice Plotino, "el afán no es estar sin error, sino ser dios". ${ }^{12}$ A las virtudes plotínicas, Porfirio añadirá las llamadas virtudes paradigmáticas, porque le interesa poner el énfasis en el carácter intelectual del ascenso hacia el Uno; en cambio, Jámblico añadirá las virtudes teúrgicas. ${ }^{13}$

Porfirio, refiriéndose a Plotino, nos cuenta:

así, sobre todo a este divino mortal, muchas veces, mientras se impulsaba a sí mismo hacia el dios primero y que está más allá, mediante sus nociones y de acuerdo con las vías indicadas por Platón en el Banquete, se le apareció aquel Dios que no tiene ni forma ni aspecto y que está asentado sobre el intelecto y sobre todo lo inteligible. A éste, entonces, también yo, Porfirio, una sola vez digo haberme acercado y haber sido unido, cuando vivía mi año sexagésimo octavo. Así pues, se apareció a Plotino, hallándose cerca el objetivo. En efecto, tenía él como fin y objetivo el ser unido y acercarse al dios que está sobre todas las cosas. Y alcanzó cuatro veces quizá, mientras conviví con él, este objetivo, por una actividad inefable y no por potencia. ${ }^{14}$

${ }^{11}$ Plot., VI, 9, 11. Véase también una expresión semejante, pero referida a la plegaria, en $\mathrm{V}, 1,6$.

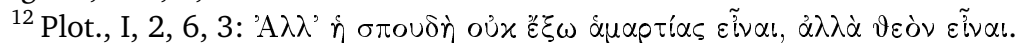

${ }^{13}$ Plot., I, 2; Porph., Sent., 32; es posible ver descrito el itinerario aretológico en la Vida de Proclo, que escribió Marino de Neápolis. Sobre la ética neoplatónica, cfr. Gregor Staab, Pythagoras in der Spätantike, Studien zu De Vita Pythagorica des Iamblichos von Chalkis (2002), pp. 155-182.

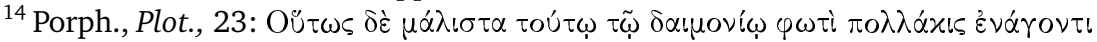

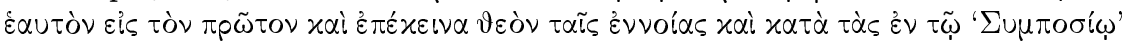

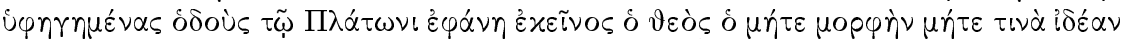

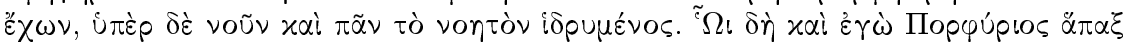

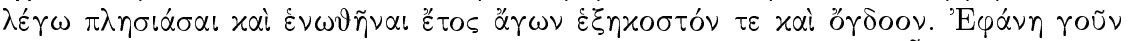

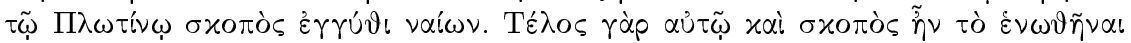

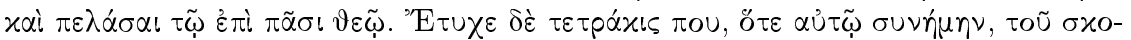

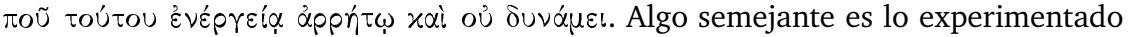
por San Pablo cuando dice refiriéndose a sí mismo: "sé de un hombre en Cristo, el cual hace catorce años — si en el cuerpo o fuera del cuerpo no lo sé, Dios lo sabe-

Diánoia, vol. LV, no. 65 (Noviembre 2010). 
Así pues, la unión con el Uno, aun para Plotino, parecía sobrevenir después de un itinerario intelectual que recorría las etapas trazadas por Platón en el Banquete.

Damascio, el último diádoco del platonismo, a propósito del desarrollo de la escuela afirma: "unos prefieren la filosofía, como Porfirio, Plotino y otros muchos filósofos; otros, la hierática, como Jámblico, Siriano, Proclo y todos los hieráticos". ${ }^{15}$ Nótese que entre los platónicos mencionados que prefieren la filosofía no hay nadie posterior a Porfirio, y que aun éste es mencionado antes de Plotino; en cambio, entre los hieráticos, el orden cronológico es progresivo y se menciona a Jámblico en primer lugar. Pero ésta no es una división tajante entre los platónicos: los hieráticos también hacían filosofía, y los filósofos también practicaban ritos, como se ve en la Vida de Plotino de Porfirio; pero el pasaje citado de Damascio señala cierto cambio de vía para unirse con el Uno, la cual muestra que, a partir de Jámblico, la teúrgia y la mántica aparecen como método, no sólo privilegiado sino único y consistente, para unirse con el principio Uno de todo lo que existe, porque dicho principio está por encima de lo racional y es fundamento de lo racional. No hay que olvidar que, después de todo, fue Plotino quien puso al Uno más allá del Intelecto, de modo que, dado el caso, a él y no a Jámblico debe reprochársele la supuesta fuga hacia lo irracional. ${ }^{16}$ Dicho de otra manera, como Jámblico merece las alabanzas que a veces se le procuran a Plotino, éste merece también las censuras que a veces se le han prodigado a Jámblico. A la distancia, ambos parecen más cercanos de lo que se pensaba, e incluso no ha faltado algún estudioso que considera la postura de Plotino derivada de las prácticas rituales contemporáneas y compatible con el modelo de teúrgo ofrecido por Jámblico. ${ }^{17}$

Cabía preguntarse, empero, sobre la causa del supuesto cambio hacia el ritual introducido por Jámblico en el neoplatonismo, y se habían propuesto varias soluciones. Para algunos, como Eduard Zeller, Jámblico representaba la antítesis irracional del racionalismo plotiniano,

fue arrebatado hasta el tercer cielo. Y sé que este hombre - en el cuerpo o fuera del cuerpo no lo sé, Dios lo sabe- fue arrebatado al paraíso y oyó palabras inefables que el hombre no puede pronunciar" (2 Co, 12, 2-4; trad. Biblia de Jerusalén).

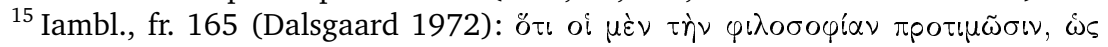

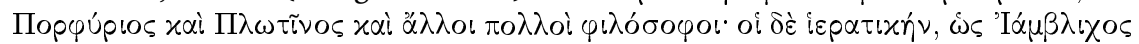

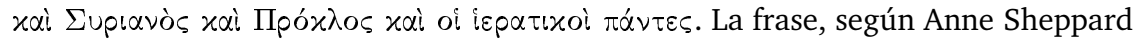
(1982, p. 212, n. 4), atribuida durante mucho tiempo a Olimpiodoro, debe atribuirse a Damascio.

${ }^{16}$ Stäcker 1995, p. 278.

${ }^{17}$ Mazur 2003 y 2004. La discusión con Beierwaltes sobre este asunto y el origen gnóstico en el pensamiento plotiniano pueden verse en Mazur 2008. 
pues había puesto a la filosofía al servicio de la religión. ${ }^{18}$ Para Dodds, el célebre autor de Los griegos y lo irracional, los filósofos platónicos, como si fueran hombres en crisis, sucumbieron ante la magia; ${ }^{19}$ se ha hablado también de Jámblico como alguien que provocó la depravación de la filosofía; ${ }^{20}$ se ha explicado la vuelta hacia el ritual como afán proselitista frente al auge del cristianismo; la explicación más socorrida fue el eclecticismo filosófico y el sincretismo religioso de la época: Jámblico sería el resultado de la irrupción de fuertes tendencias orientalizantes que habrían desvirtuado la racionalidad griega. Esta explicación parecía confirmada por el hecho de que la única obra de Jámblico que se conserva completa era más conocida por el título que le dio Marsilio Ficino en su traducción latina: Acerca de los misterios de los egipcios, de los caldeos y de los asirios.

El verdadero título de la obra es Respuesta del maestro Abamón a la "Epístola a Anebón" de Porfirio, y soluciones de las dificultades que se encuentran en ella. Se trata de la parte resolutiva de una investigación emprendida por Porfirio mediante la formulación de preguntas y el planteamiento de dificultades. La mencionada Epístola a Anebón de Porfirio, hoy perdida, no sólo cuestionaba sino que, más bien, ironizaba a quienes hacían de los ritos la vía de acceso para unirse con el Uno. Por ejemplo, Porfirio cuestiona que los dioses pidan que quien hace un sacrificio esté libre de contactos sexuales, mientras los dioses mismos no vacilan en llevar a cualquiera a concúbitos deshonestos. O igualmente cuestiona que los dioses pidan abstinencia de carne cuando el sacrificio mismo se hace precisamente mediante la inmolación de víctimas animales. San Agustín, en La ciudad de Dios, ofrece un resumen de esa Epístola de Porfirio y hace ver cómo el erudito filósofo finge investigar para no herir las susceptibilidades de cierto sacerdote egipcio de nombre Anebón. ${ }^{21}$ Jámblico, al parecer, tocado por la ironía de Porfirio, se asume como el maestro del destinatario original y toma como pseudónimo el nombre de Abamón para contestar a Porfirio sus planteamientos con respecto a la teúrgia.

Leyendo sin prejuicios a Jámblico es posible percatarse de que su postura respecto de la unión con el Uno mediante la teúrgia obedece a

${ }^{18}$ Zeller 1968, pp. 3-11, 44-46.

${ }^{19}$ Dodds 1984, p. 288.

${ }^{20}$ Zintzen 1965; más tarde, el mismo Zintzen (1983) matiza su postura y considera la posición de Jámblico como un intento de poner en consonancia la teúrgia con la ontología plotínica y la consiguiente espiritualización de la teúrgia.

${ }^{21}$ Aug., C.D., X, 11.

Diánoia, vol. LV, no. 65 (Noviembre 2010). 
razones metafísicas. ${ }^{22}$ Mientras Porfirio ponía al intelecto en contacto inmediato con el Uno, e incluso consideraba al Uno meramente como la parte superior del intelecto, Jámblico tiene interés en recuperar la absoluta trascendencia del primer principio. Esto queda claro en el siguiente fragmento, cuando Damascio se ocupa de examinar precisamente los primeros principios:

examinemos —dice Damascio- lo siguiente: si son dos los primeros principios antes de la primera tríada inteligible, el absolutamente inefable y el no coordinado con la tríada, como pensó el gran Jámblico en el libro 28 de su perfectísima Teología caldaica, o si, como opinó la mayoría posterior a él, después de la causa inefable y única está la primera tríada de los inteligibles, o también descenderemos de esta hipótesis y diremos, según Porfirio, que el único principio de todo es el padre de la tríada inteligible. ${ }^{23}$

Frente a la postura de Plotino, Porfirio pierde el carácter trascendente de la unión con el Uno; para él, esa unión era en el fondo unión del intelecto consigo mismo; Jámblico se esfuerza por recuperar ese carácter trascendente y totalmente inefable del primer principio, aunque para ello y para atajar completamente la posición de Porfirio, a la que consideraba soberbia, limitó el papel del intelecto en la consecución de la unión con el primer principio.

Por otro lado, según Jámblico, Plotino se equivocaba porque había postulado que una parte del alma nunca desciende al cuerpo y permanece unida a las realidades inteligibles. ${ }^{24}$ Para Jámblico, el alma entera, incluso antes de encarnarse en un cuerpo, es responsable de sus errores, y aun habiendo descendido a un cuerpo, el alma mantiene su capacidad de elección, y aunque el mundo al que desciende no es del todo un ámbito determinista, hay que pensar que, cuando un alma

${ }^{22}$ Stäcker 1995.

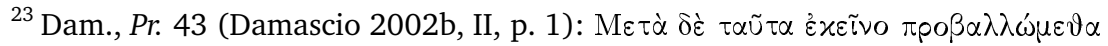

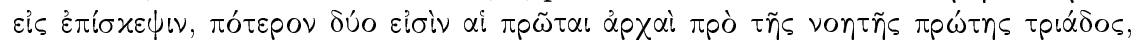

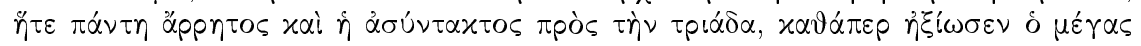

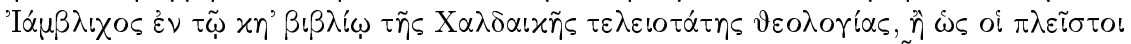

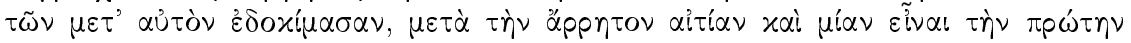

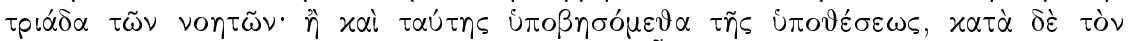

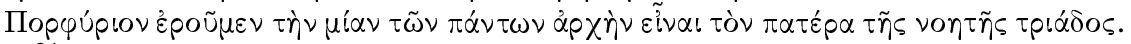

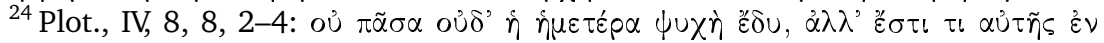

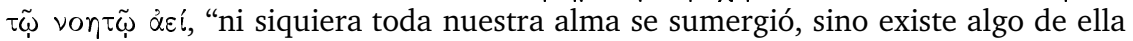
siempre en lo inteligible". El libro de consulta obligado para el tema de la posición de Plotino sobre la parte del alma que no se encarna del todo, y, sobre todo, para el criticismo iniciado por Jámblico, es, por supuesto, The Changing Self de Steel (1978).

Diánoia, vol. LV, no. 65 (Noviembre 2010). 
desciende a un cuerpo, lo hace toda ella. ${ }^{25}$ Es más, para Jámblico, si el alma se encarna en un cuerpo no se debe solamente a que deba expiar alguna de sus culpas pasadas, ni, como dice Plotino, a una osadía por la cual, volcada hacia la materia, se olvida de su dios y padre ${ }^{26}$ para Jámblico, existen almas mandadas para instruir a las otras como las de Pitágoras o Platón, almas de una categoría superior que descienden para "salvación, purificación y perfección" 27 de este mundo; pero todas las otras almas, aun las comunes, al menos en su primer nacimiento, fueron enviadas a propósito por dios, con la consigna de volver a él: "dios envió abajo a las almas para esto, para que de nuevo regresaran hacia él". ${ }^{28}$ Así pues, el descenso de las almas no obedece siempre a una transgresión en el orden del universo, como es el caso en el gnosticismo, sino que, en conformidad con el Timeo de Platón, el universo es uno, los dioses lo gobiernan mediante un orden armonioso donde las almas, al encarnarse, también cumplen una función específica dentro de ese orden. Estar en un cuerpo y estar en el mundo, piensa Jámblico, no es necesariamente un mal, antes bien, tiene un propósito en la administración del universo. Es probable que esta visión que pone énfasis en la total encarnación del alma en un cuerpo, así como la postulación de la teúrgia como modo de unirse a dios, se deba más a la influencia de Aristóteles en el pensamiento de Jámblico que a cierto pesimismo del que se le ha acusado, o a influencias de las religiones orientales a que vagamente se alude para explicar el giro de Jámblico hacia la teúrgia. ${ }^{29}$

${ }^{25}$ Iambl., In Tim. fr. 87 (Dillon 1973).

${ }^{26}$ Plot., V, 1, 1.

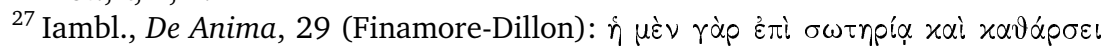

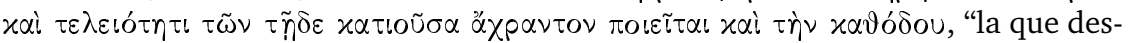
ciende (sc., el alma) para salvación y purificación y perfección de las cosas de aquí emprende también sin mancha el descenso". Probablemente Plotino pensaba en estas almas cuando decía que una parte de las almas se mantenía en permanente unión con el orden inteligible. Sobre el tema del descendimiento del alma en Jámblico, cfr. Dillon 1980.

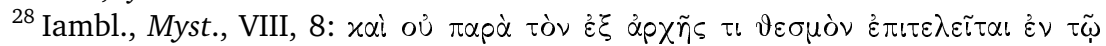

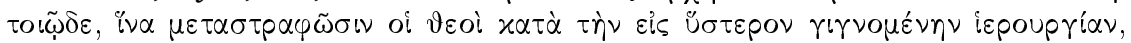

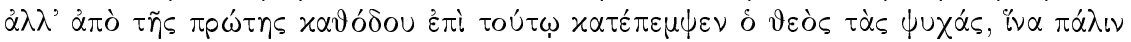

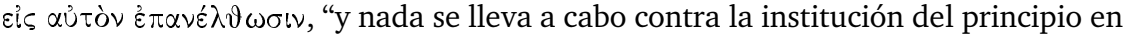
tal situación, para que los dioses cambien de acuerdo con la obra sagrada posterior, sino desde el primer descenso, dios envió abajo a las almas para esto, para que de nuevo regresaran hacia él".

${ }^{29}$ Shaw 1995, p. 95: "sugeriría que la diferencia entre Jámblico y Plotino con respecto a las prácticas rituales podría haber sido determinada, no por los supuestos

Diánoia, vol. LV, no. 65 (Noviembre 2010). 
Por otra parte, a propósito de la relación del alma con el intelecto, también hay que distinguir entre el orden superior del intelecto y el orden inferior del alma, lo que al parecer solía confundirse entre los platónicos:

Jámblico —afirma Proclo- entiende que este intelecto es más importante que el alma, porque desde arriba la contiene y la perfecciona, y contiende o bien contra quienes ponen en contacto inmediatamente al alma con el intelecto total (pues es preciso que la transición no se dé toda a la vez desde los trascendentes hacia los participantes, sino que haya esencias intermedias que se coordinen con los participantes) o bien contra quienes suponen que el intelecto es una disposición del alma (pues es preciso que lo que es en sí mismo sea antes de lo que es en otro). ${ }^{30}$

Así pues, existe en Jámblico, por un lado, un principio de todas las cosas totalmente trascendente, tan distinto de todo lo que existe que no hay posibilidad alguna de que el intelecto pueda confundirse con él, y, por el otro, un alma humana, claramente diferenciada del intelecto, encarnada toda en un cuerpo. Es más, de acuerdo con Jámblico, hay que distinguir absolutamente la hipóstasis del Alma de la del Intelecto, pues ésa es la verdadera doctrina sostenida por los más grandes maestros de la antigüedad. En un fragmento de su tratado Sobre el alma, Jámblico afirma:

Ahora bien, la doctrina contrapuesta [a la que considera unida el alma al intelecto] separa al alma, como generada en segundo lugar, a partir del intelecto, en otra hipóstasis, y en cuanto a lo que de ella está con intelecto, explica que, aunque dependiente del intelecto, subsiste de manera autónoma junto con lo que está en su propia hipóstasis, y la separa también de todos los géneros superiores, y le distribuye un límite propio de su esencia,

antecedentes orientales de Jámblico, ni por su atracción hacia las prácticas religiosas exóticas de su tiempo, sino por la influencia más profunda de la psicología de Aristóteles sobre Jámblico que sobre Plotino". El mismo Shaw afirma en otra parte (1993, p. 117): "Jámblico implicó al alma en el cuerpo y en la vida corporal mucho más extensamente que Plotino, y esto, creo, se debió a que la psicología de Aristóteles tuvo mayor influencia sobre Jámblico que sobre Plotino."

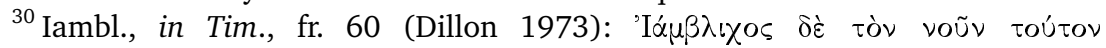

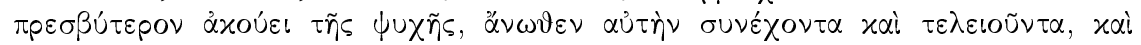

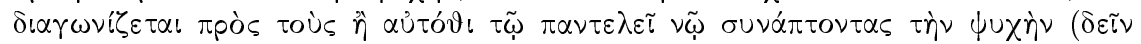

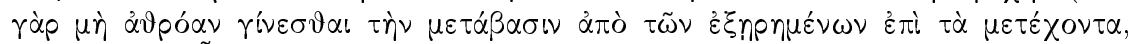

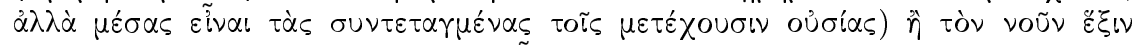

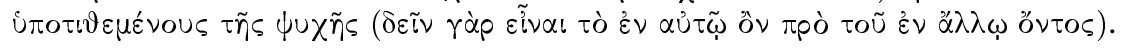

Diánoia, vol. LV, no. 65 (Noviembre 2010). 
o bien el término medio entre los géneros divisibles y los indivisibles, y entre los corpóreos y los incorpóreos, o la plenitud de las razones universales, o el servicio, después de las ideas, de la creación, la vida que de sí misma tiene el vivir, que procede desde lo inteligible, o a su vez la procesión de los géneros de todo el ser verdadero hacia la esencia inferior. En torno a estas doctrinas se vuelven perfectamente Platón mismo y Pitágoras, y Aristóteles y los antiguos todos, cuyos grandes nombres se alaban por su sabiduría, si alguno siguiera con ciencia las huellas de sus doctrinas. ${ }^{31}$

En Jámblico, pues, a diferencia de Porfirio, ocurren dos cosas: por una parte, recupera el carácter trascendente del primer principio, por la otra, considera el alma humana enteramente encarnada en un cuerpo; estos dos factores implican, primero, perder al intelecto como instrumento de unión con el Uno, aunque cabe recordar que ya para Plotino la unión con el Uno tenía un carácter que sobrepasaba al intelecto; y, segundo, buscar un medio adecuado a la situación del alma mientras está en el cuerpo, un medio que le permita emprender el ascenso hacia el Uno. La solución no puede ser el intelecto, porque incluso la unión con la más venerable y unificada de las hipóstasis inteligibles no puede realizarse mediante procedimientos gnoseológicos propios del alma o del intelecto; de acuerdo con el testimonio de Damascio, según Jámblico eso es imposible:

Así pues, que aquel [principio] no es comprensible ni por opinión, ni por pensamiento discursivo, ni por el intelecto anímico ni por intelección acompañada de razonamiento, y que ni siquiera es alcanzable por la vigilancia perfecta del intelecto ni por la flor del intelecto, ni es conocible en absoluto por intuición ni según un determinado apoyo ni según compren-

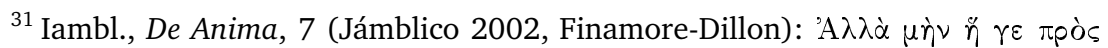

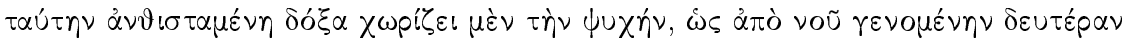

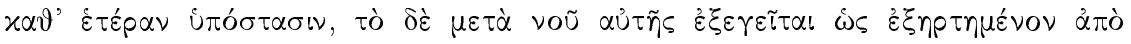

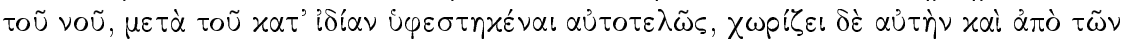

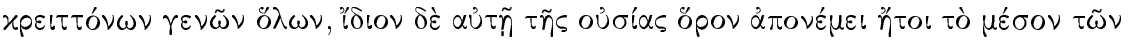

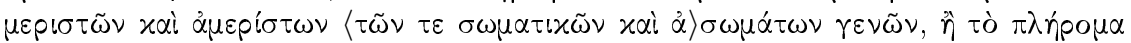

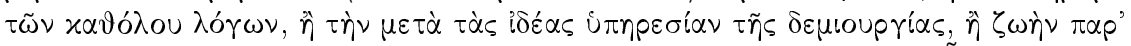

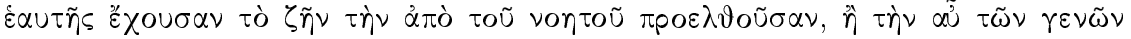

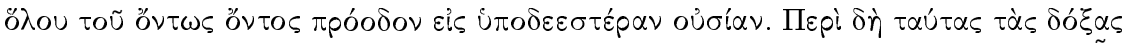

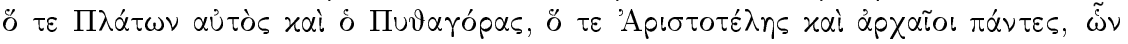

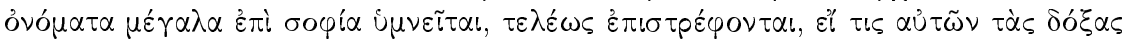

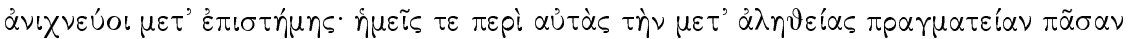

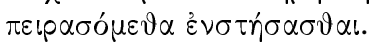

Diánoia, vol. LV, no. 65 (Noviembre 2010). 
sión ni de algún modo semejante, debe ser concedido al gran Jámblico, que sostenía estas cosas. ${ }^{32}$

La solución, entonces, fue la teúrgia, pues en ella los géneros superiores al alma la ayudan a emprender su camino de regreso hacia el Uno, y la unión teúrgica no depende del intelecto:

la unión teúrgica con los dioses — dice Jámblico— se basa en la eficacia de las obras -inefables y realizadas como conviene a lo divino, por encima de toda comprensión-, y en la potencia de los símbolos, inexpresables, comprensibles sólo por los dioses. Por eso no realizamos esas cosas porque las entendemos, pues en tal caso su actividad sería intelectual y producida por nosotros; mas ni una ni otra cosa son verdaderas. En efecto, incluso no comprendiéndolas nosotros, las contraseñas mismas realizan por sí mismas su obra propia, y la potencia inefable de los dioses, hacia los cuales se elevan estas contraseñas, reconoce por sí misma sus propias imágenes, mas no porque se despierten por nuestra intelección. ${ }^{33}$

La lectura que Jámblico hace del Parménides de Platón, de acuerdo con el testimonio de Proclo, confirma que la postulación jambliqueana de la teúrgia obedece a razones metafísicas:

Después de éstos, los que introducen los seres, de acuerdo con otro modo, son los que dicen que la primera hipótesis es sobre dios y dioses; pues dicen que ella hace el discurso no sólo acerca del uno, sino también acerca

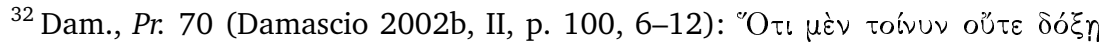

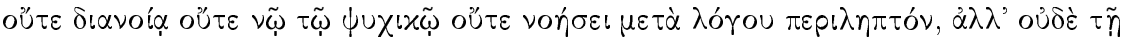

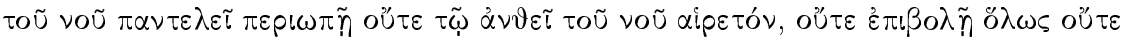

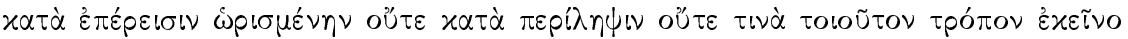

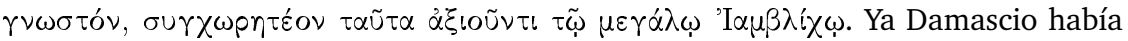
señalado anteriormente que, "según Jámblico, tampoco mediante las contemplaciones del intelecto se piensa el punto más alto de lo inteligible" (Damascio 2002b,

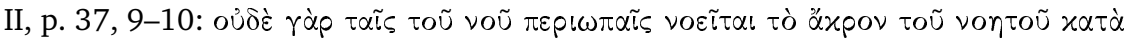
'Í́ußi

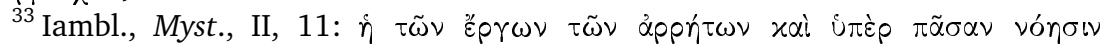

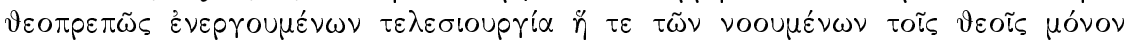

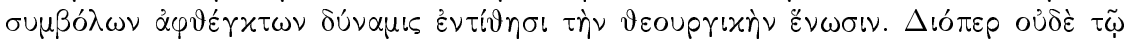

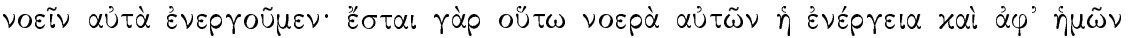

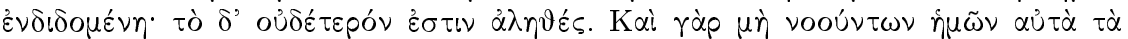

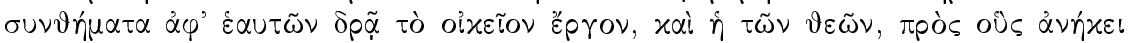

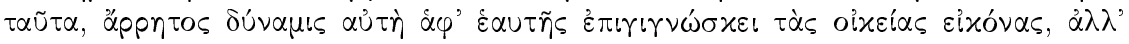

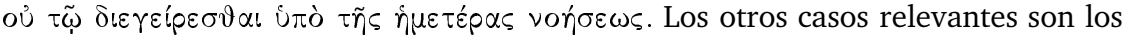
símbolos, en Iambl., Myst., VII, 1, y los nombres ininteligibles que se usan en el culto, en Iambl., Myst., VII, 4-5.

Diánoia, vol. LV, no. 65 (Noviembre 2010). 
de todas las divinas hénadas; la segunda, acerca de la extensión inteligible y de los dioses inteligibles; la tercera, todavía no lo hace acerca del alma, como los anteriores, sino acerca de los géneros superiores a nosotros: ángeles, demonios, héroes (pues dicen que estos géneros dependen inmediatamente de los dioses y son superiores incluso a las almas universales mismas; esto afirman, como lo más extraordinario, y por esto comprenden el orden en las hipótesis antes de las almas); la cuarta, acerca de las almas racionales; la quinta, acerca de las almas segundas que se entretejen con las almas racionales; la sexta, acerca de las formas implicadas en la materia y de todas las razones seminales; la séptima, finalmente, acerca de la materia misma; la octava, acerca del cuerpo celeste; la novena, acerca del cuerpo generado y sublunar. ${ }^{34}$

Jámblico pone, pues, en la primera hipótesis, no sólo al Uno inefable, sino a dios y los dioses; después, en la segunda, coloca el ámbito inteligible, pero en la tercera hipótesis, Jámblico coloca no al alma, sino a los géneros superiores: ángeles, héroes, demonios, y sólo hasta la cuarta hipótesis pone a las almas. Es decir, para Jámblico, desde el punto de vista de la procesión, el primer principio queda por encima de todo, $\mathrm{y}$

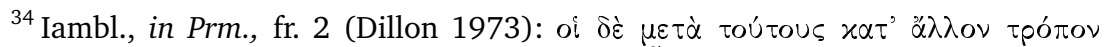

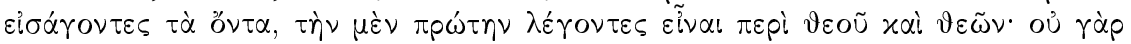

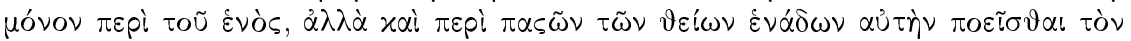

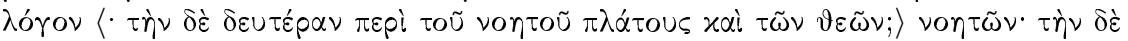

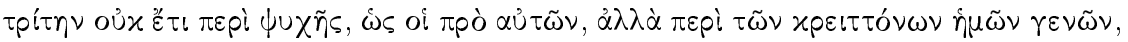

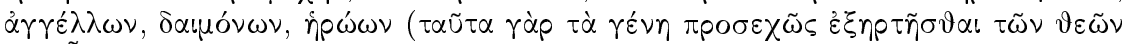

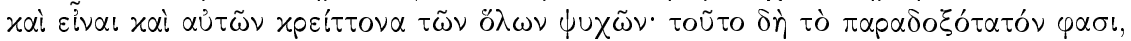

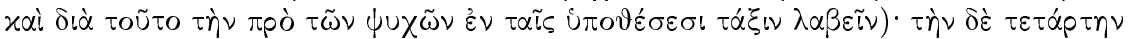

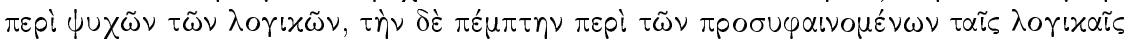

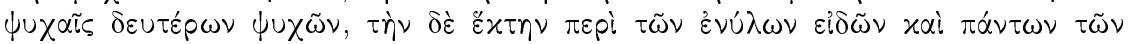

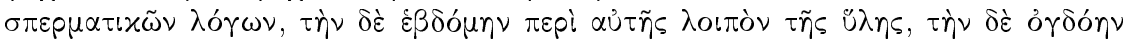

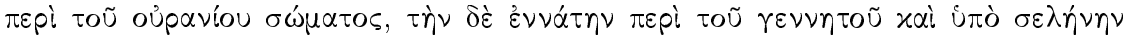

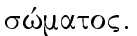

Para la comparación entre Porfirio y Jámblico con respecto a su interpretación del Parménides, cfr. Dillon 1973, pp. 387-389; Saffrey y Westerink, en Proclo 1978, pp. XXVIII-XXIX; Dillon 1988, y Steel 1997. Proclo criticó las interpretaciones de Porfirio y Jámblico, porque en ellas no todas las hipóstasis fungen como principios: en el caso de Porfirio, las últimas repiten sus elementos, y, en el caso de Jámblico, la inclusión de ángeles, demonios y héroes en la tercera hipóstasis no es adecuada según él, porque no es claro si pertenecen al orden intelectivo o al anímico (Proclo 1968, pp. LXXXI-LXXXII). A propósito de las interpretaciones de Amelio, anterior a Porfirio, y de otros neoplatónicos posteriores a Jámblico (Teodoro de Asina, Plutarco de Atenas, Siriano, los cuales consideraron el grupo de las hipótesis no como una procesión continua, sino como dos grupos alternativos de hipóstasis, positivas y negativas), cfr. Proclo 1968, pp. LXXX-LXXXIX; y J. Combès, en Damascio 2002a, pp. XII-XIV. 
los dioses fungen como una mediación entre ese principio y el ámbito inteligible; además, entre las almas y el ámbito inteligible, Jámblico introduce, desde el punto de vista de la regresión, los géneros superiores como paso intermedio: los héroes, los demonios, las almas racionales. Dicho de otro modo, para unirse con el Uno, el intelecto no puede ser una vía inmediata, y tampoco es inmediato el acceso del alma de los seres humanos con el intelecto; debe pasarse antes por esos géneros superiores, y, finalmente, para llegar al primer principio, después de unirse al intelecto, el alma debe unirse a los dioses que la ayudarán en el cumplimiento final de su ascenso.

Cabe hacer notar que, para Jámblico, en las últimas tres hipótesis, de la séptima a la novena, se hallan la materia, el cuerpo celeste y el cuerpo generado y sublunar. El asunto es importante si se considera el contexto en que Jámblico aparece; a su lado están los gnósticos, el maniqueísmo, corrientes de pensamiento que consideraban una realidad escindida, donde la materia era vista como principio del mal, de la que había que apartarse; doctrinas a cuyo influjo el mismo Plotino, aunque combatiéndolas, no pudo escapar del todo, pues él mismo llegó a hablar de la materia como del "mal en sí mismo". ${ }^{35}$ Sin embargo, atendiendo

${ }^{35}$ Plot., I, 8, 3: xavåuitò xaxóv. Según Jonas (2000, pp. 187 s.), el texto de Jámblico de Myst., VIII, 6 -donde señala que el ser humano tiene dos almas, una perteneciente al mundo inteligible y otra originada con la revolución de los cielos-, es un rasgo gnóstico y muestra claramente la base que sustenta la fantasía mitológica de esta doctrina del alma "planetaria": la escisión entre el hombre y la naturaleza, que implica el rechazo del universo físico a la luz del pesimismo; en lo más profundo, el hombre no pertenece a este mundo. Sin embargo, para Jámblico la naturaleza no está escindida del ser humano, sino que el alma humana es doble por naturaleza (Steel 1978) y el mundo puede ser también receptáculo apto de la acción de los seres superiores, e incluso hay una materia "pura y divina" (Iambl., Myst., V, 23); además, el alma puede encarnarse en un cuerpo no sólo para expiar sus faltas cometidas en vidas anteriores, sino también para cumplir con un designio divino, pues los dioses pueden enviarla para que regrese a ellos (Iambl., Myst., VIII, 8). Las coincidencias con los gnósticos pueden verificarse, pero no en el sentido que señala Jonas: Edwards (1997, p. 203) muestra algunas semejanzas con Jámblico, porque fueron los gnósticos quienes hablaron de la materia como una "sustancia bendita", y quienes, junto con los pitagóricos, construían el mundo con base en la numerología; sin embargo, dice el mismo Edwards, esas similitudes pueden explicarse no por influencia histórica directa, sino por el hecho de que quienes comparten la misma época y la misma sociedad pueden tener las mismas creencias, y porque pensadores movidos por distintos intereses y con métodos distintos pueden llegar a veces a los mismos resultados. Por otro lado, Pearson muestra cómo algunas de las prácticas rituales de los gnósticos podían entenderse en los términos en que Jámblico explica la teúrgia, dejando claro que los ritos gnósticos y los de la teúrgia no son

Diánoia, vol. LV, no. 65 (Noviembre 2010). 
a su interpretación del Parménides, para Jámblico la realidad es una sola; es decir, su visión es monista pero jerárquica, y en ella la materia recupera una bondad primordial que ya estaba presente, por cierto, en el Timeo de Platón.

Así pues, la solución que Jámblico encontró frente a la postura de Porfirio, la cual él encontraba desbordada en sus pretenciones intelectuales, fue el ritual, la teúrgia; en ésta ocurren varias cosas: el Uno mantiene su trascendencia; la divinidad conserva su supremacía absoluta sobre lo intelectual, pues el intelecto mismo se subordina frente a lo divino; el ser humano, conservando su lugar en la jerarquía, sin soberbia intelectual, puede encontrar un camino de ascenso hacia el Uno, incluso mediante la materia, la cual los dioses y los demás géneros superiores utilizan voluntariamente para manifestar su poder y para ayudar al ser humano. Dice Jámblico:

Que nadie se admire, pues, si decimos que también ciertas materias son puras y divinas; en efecto, habiendo sido creadas por el padre y demiurgo del todo, poseen esa perfección que es adecuada para recibir a los dioses. Y además, no hay ningún impedimento para que los superiores puedan iluminar a sus inferiores, y, por consiguiente, nada separa a la materia de la participación de los bienes mejores, de modo que cualquier materia que sea perfecta y pura y poseedora de la forma del bien es apta para el recibimiento de los dioses; así pues, ya que las cosas terrestres de ninguna manera debían estar privadas de la comunión divina, también la tierra recibió cierta porción divina de ella, una que es capaz de dar lugar a los dioses. $^{36}$

los mismos ni por su contenido ni por su fondo mitológico. Pearson también hace ver que algunos textos gnósticos, tales como Estelas de Seth o Marsanes, presentan rasgos en su cosmovisión compatibles con el optimismo platónico, y por ende, son cercanos a Jámblico y a su visión del mundo y de la materia; asimismo, Jámblico, dice Pearson, no debe ser tenido como un gnóstico, pero, aunque debió de disentir de las visiones gnósticas referentes a la desviación del alma, consideró esas visiones dignas de ser mencionadas; además, Jámblico podría no haber compartido el criticismo de Plotino respecto de la actividad ritual de los gnósticos.

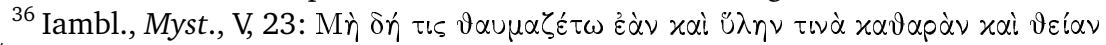

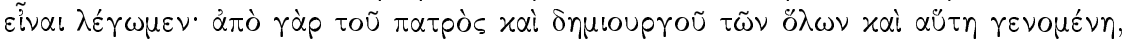

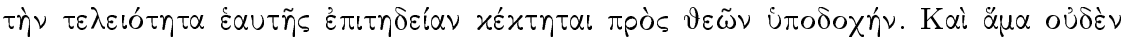

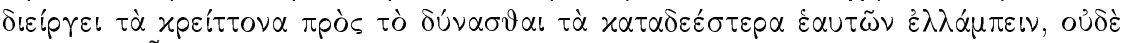

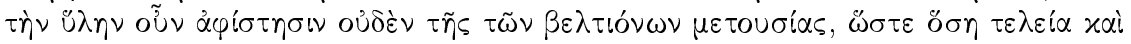

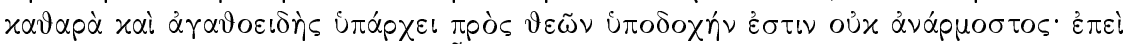

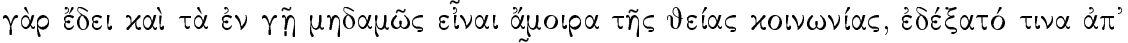

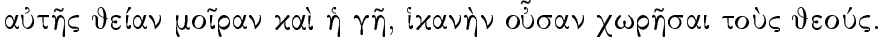

Diánoia, vol. LV, no. 65 (Noviembre 2010). 
Ahora bien, para Jámblico, la teúrgia consigue tres resultados fundamentales, ordenados progresivamente: purificación, liberación del destino y unión con los dioses. ${ }^{37}$ Estos objetivos los realizan los dioses en los hombres mediante los ritos que los dioses mismos han prescrito, con las palabras y objetos que ellos mismos han señalado. De manera que los objetivos del culto tienen más que ver con los efectos en los seres humanos mediante la acción divina, siempre presente en el universo, que con los pretendidos efectos que los hombres mediante el culto quisieran tener sobre los dioses, como pensaba Porfirio. La teúrgia, a diferencia de la magia, no busca la manipulación de la divinidad. La teúrgia debe tener un orden que depende de la situación concreta del ser humano, de su grado de apego a (o desapego de) lo material, y también de la divinidad a la que se ofrece el culto, de manera que el culto es progresivo en correspondencia con la aptitud que el hombre va ganando para, por decirlo de una manera, sintonizarse con la acción benéfica de los dioses. ${ }^{38}$ Un ejemplo concreto de ello es la plegaria, de la que existen tres clases correspondientes al estado que guarda el alma en su proceso de unificación con la divinidad:

la primera clase de plegaria es una de recogimiento y que precede a la conexión con lo divino y a su conocimiento. La siguiente es una que logra la comunión armónica en el intelecto y provoca, antes que nuestra razón, los dones que descienden de los dioses y que cumplen todas las obras antes de que uno lo piense; y la más perfecta clase de plegaria concluye con un sello la unión inefable del alma con la divinidad, en cuanto que

${ }^{37}$ Estos tres resultados se formulan de maneras distintas; en Iambl., Myst., I, 12

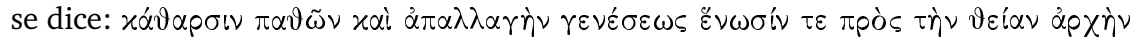

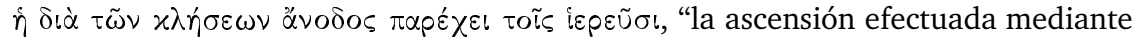
invocaciones proporciona a los sacerdotes purificación de sus pasiones, liberación del lastre de la generación, y unión con el principio divino"; en Iambl., Myst., V, 26,

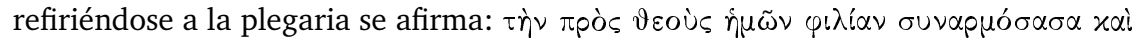

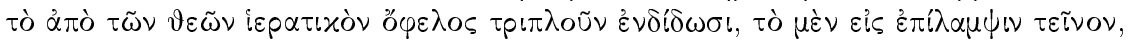

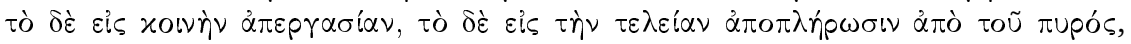
“[sc., la plegaria] al armonizar nuestra amistad con los dioses, también nos entrega triplemente la sagrada utilidad de parte de los dioses: una, la que tiende a la iluminación; otra, a la eficacia general, y otra, a la perfecta plenitud del alma por el fuego"; en Iambl., Myst., X, 7 la expresión es la siguiente: oủō̇ $\pi \varepsilon \rho i ̀ ~ \sigma u i x p \tilde{u} \nu$

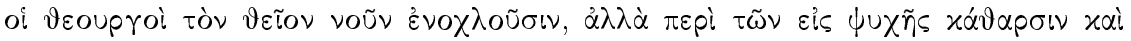

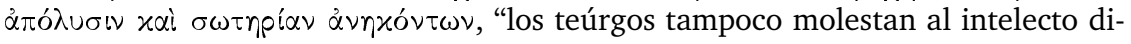
vino en cosas pequeñas, sino en las que se refieren a la purificación, liberación y salvación del alma".

${ }^{38}$ Iambl., Myst., V, 14-20.

Diánoia, vol. LV, no. 65 (Noviembre 2010). 
dicha unión fundamenta en los dioses toda su validez y hace que nuestra alma descanse perfectamente en ellos. ${ }^{39}$

Poco a poco, después de un camino largo, la unión con el Uno puede consumarse mediante un ascenso cuyos pasos previos, todos, deben cumplirse, y eso lleva su tiempo. La unión con el Uno no exime de la unión con todos los órdenes superiores previos, y más bien la exige. ${ }^{40}$ Para decirlo coloquialmente, Jámblico no suscribiría el dicho de "estando yo bien con dios, me río de sus angelitos". Para él, antes de llegar a la unión con el Uno, debe seguirse un proceso y método que gradualmente consigue la unión con todos los órdenes subalternos:

¿Pues qué? —pregunta Jámblico-. ¿Lo más alto de la hierática no se remonta hacia el Uno mismo, que es más soberano que la multitud entera, y en él al mismo tiempo sirve juntamente a las muchas esencias y principios? Yo lo afirmaría, y totalmente; sin embargo, esta aspiración se logra muy tardíamente y sólo en muy pocos, y hay que contentarse con que se consiga en el ocaso de la vida, y sólo en alguna ocasión. ${ }^{41}$

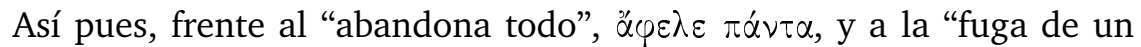

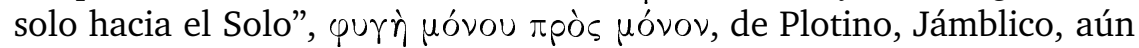
antes de unirse con el principio supremo, convierte el universo en instrumento para su regreso hacia el Uno. La superioridad de los dioses no les impide actuar en los niveles inferiores de la realidad ni en los lugares terrenales, ${ }^{42}$ y el ser humano no sólo puede, sino que debe valerse de esos niveles inferiores para ascender hacia los superiores, pues "de acuerdo con el arte de los sacerdotes es necesario comenzar las obras sagradas a partir de los materiales, pues de otra manera no se daría el ascenso hacia los dioses inmateriales". ${ }^{43}$

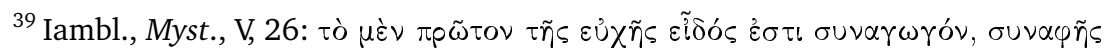

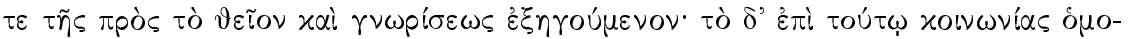

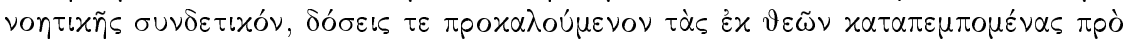

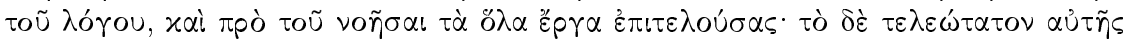

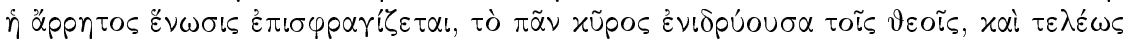

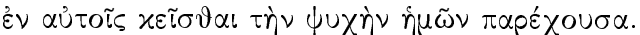

${ }^{40}$ Iambl., Myst., V, 15; V, 21.

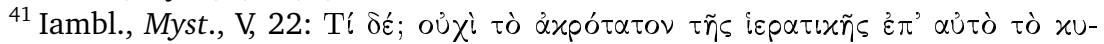

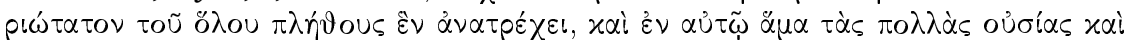

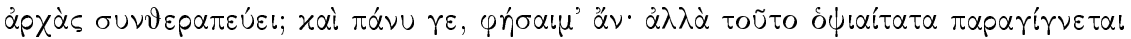

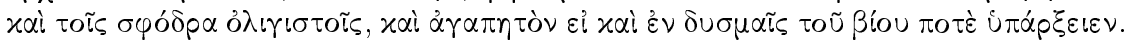

${ }^{42}$ Iambl., Myst., I, 8.

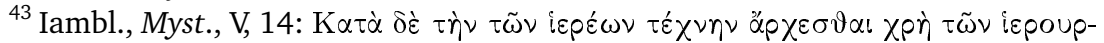

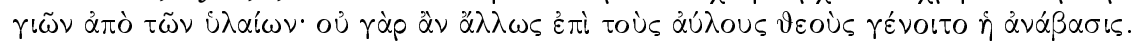

Diánoia, vol. LV, no. 65 (Noviembre 2010). 
Es cierto que la posición de Plotino puede recibir muchas precisiones y matices; también es cierto que Jámblico, como en otros casos, simplifica y exagera acaso la posición de Plotino para poner énfasis en su propia tesis, una donde el ascenso de cada alma presupone la unión con las demás, pues en el camino hacia el Uno debe haber reconciliación con el cosmos, con todas las entidades que el alma va encontrando en su camino, ${ }^{44}$ y también con las otras almas, lo cual, me parece, abre la posibilidad de una "religiosidad" (si se puede llamarla así) que rechaza toda enajenación, que puede, incluso, tener consecuencias sociales o políticas, y que acaso tenga su principal motivación en la raigambre pitagórica de su pensamiento. ${ }^{45}$ De hecho, en el tratado Acerca de la vida pitagórica, Pitágoras suponía que el gobierno de los dioses es lo más eficaz para establecer la justicia, y desde dicho gobierno disponía la forma de gobierno, las leyes, la justicia y las cosas justas. ${ }^{46}$

Un ejemplo del aspecto comunitario de la teúrgia, aunque en cierto sentido negativo, porque no se trata del ascenso hacia dios, aparece en la Respuesta a Abamón, cuando se afirma que una culpa demasiado grande no puede ser expiada por la sola alma que la comete. Dice Jámblico:

¿Qué impide, pues, que lo justo para cada hombre, en particular y en consideración a todo el parentesco de las almas, sea juzgado por los dioses muy diferentemente? En efecto, si la comunión de su misma naturaleza efectúa en las almas —en las almas que están en los cuerpos y en las que están sin cuerpos- un mismo enlace en la vida del cosmos y un orden común, entonces también es necesario que la multa de la pena sea reclamada al todo, y máxime cuando la magnitud de las injusticias cometidas antes por una sola supera la satisfacción que una sola puede hacer del castigo correspondiente a sus delitos. ${ }^{47}$

${ }^{44}$ Véanse los artículos de G. Shaw, "Theurgy as Demiurgy: Iamblichus' Solution to the Problem of Embodiment" (1988), y "Theurgy: Rituals of Unification in the Neoplatonism of Iamblichus" (1985).

${ }^{45}$ Véase, por ejemplo, O’Meara 1993.

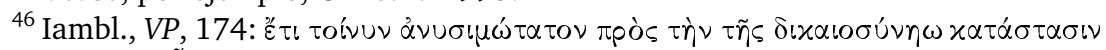

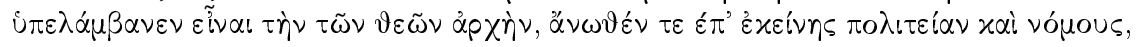

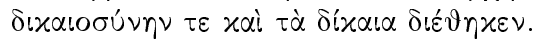

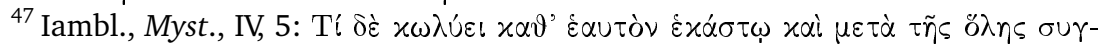

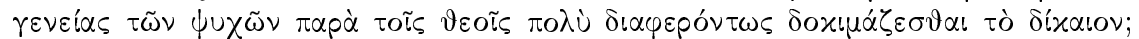

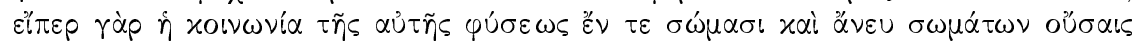

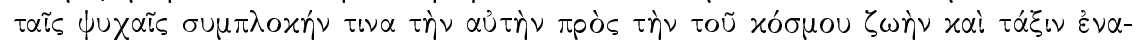

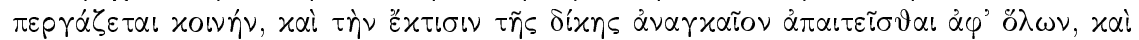

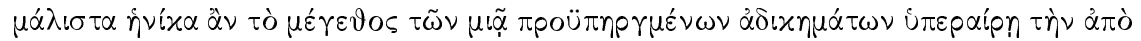

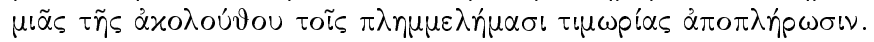

Diánoia, vol. LV, no. 65 (Noviembre 2010). 
Así pues, la comunión de naturaleza provoca "un mismo enlace en la vida del cosmos y un orden común", y por eso un alma que haya infringido el orden provoca que no sólo ella pague la pena correspondiente; como se ve, y para decirlo coloquialmente, todos estamos en el mismo barco. Existe otro texto donde esta unidad proclamada por Jámblico aparece también en cierta manera negativa, pero no tan claramente. Se trata del capítulo veinte de su Protréptico, cuando cita al sofista anónimo del siglo $\mathrm{V}$ a.C. Allí se habla de cómo sólo aparentemente la tiranía se impone, pues la verdadera causa de la tiranía, amén de la falta de leyes y de la ambición del que gobierna, es la inclinación de todos a la maldad. Dice el anónimo:

creen algunos hombres - los cuales no conjeturan correctamente, porque no reflexionan sobre estas cosas correctamente- que el tirano se establece por una causa distinta [de la falta de leyes] y que los hombres son despojados de su libertad, sin ser ellos culpables, sino violentados por el tirano que se ha establecido. En efecto, cualquiera que considera que un rey o un tirano surge por alguna razón distinta de la falta de leyes y de la ambición es un insensato. Pues cuando todos se inclinan a la maldad, entonces nace esto. ${ }^{48}$

Se colige del texto que los hombres también son culpables de perder su libertad y que el tirano surge cuando todos se inclinan a la maldad. La tiranía es, pues, otra cara de la anarquía, y todas las demás personas, por su común inclinación a la maldad, están unidas como causa del surgimiento del tirano. El tema concreto de la relación entre tiranía y anarquía, por supuesto, también está tratado en los diálogos platónicos; ${ }^{49}$ pero lo que aquí se sugiere en términos políticos - aunque, como dije, por vía negativa- es la unión que también debe darse en otros planos; debe darse, diríamos, como en el primer ejemplo, en el plano escatológico de la salvación de las almas; plano que, a su vez, involucra conjuntamente a la ética, a la cosmología y a la ontología. En otras palabras, el camino del ascenso trazado por Jámblico no puede ser caracterizado como una mística escapista, sino como una mística

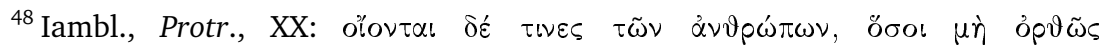

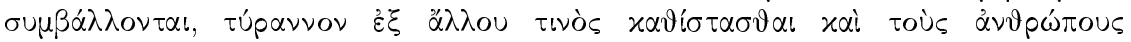

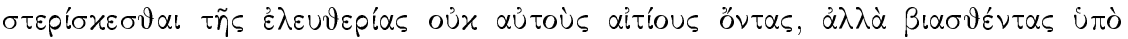

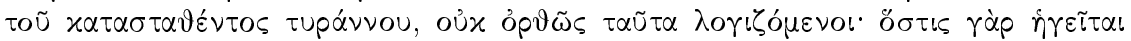

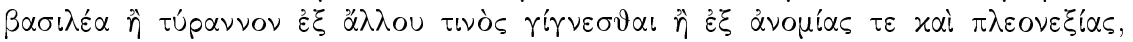

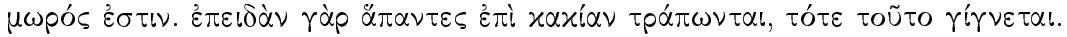

${ }^{49} \mathrm{Pl}$., R., VIII, 555b-570e. La constitución mixta de las Leyes pretende, precisamente, acotar al mismo tiempo los vicios de la monarquía y la democracia.

Diánoia, vol. LV, no. 65 (Noviembre 2010). 
que no puede cumplirse a menos que se construyan o se reconstruyan adecuadamente los vínculos con el cosmos y con las demás almas, y esto va más allá de una simple revaloración de la materia. A ello apunta, me parece, lo que Jámblico, en clara oposición con las declaraciones plotinianas, señaló en otras partes, de acuerdo con el importante y claro testimonio de Damascio: "Jámblico afirma que el ascenso hacia el Uno no es alcanzable para nadie, si no se coordina a sí mismo con todos, y junto con todos regresa hacia el principio común de todos."50 En ese mismo sentido, en la Respuesta de Abamón, IV, 3, al distinguir las acciones humanas de las divinas, Jámblico menciona una unión, provista por los dioses, de implicaciones ontológicas, la cual es necesaria para que la acción realizada en el rito sea considerada divina. Afirma Jámblico: "si la comunión de una amistad armónica en el intelecto y cierto enlace indisoluble contienen la producción sagrada, para que sea verdaderamente divina y sea superior a toda acción cognoscente común a los hombres, nada dicho de las obras humanas se ajusta a ella"; en el rito, continúa Jámblico, la actividad del fuego divino "actúa a través de todos los que la comunican y de los que al mismo tiempo pueden tomar parte de ella". ${ }^{51}$ Esa misma "amistad armónica en el intelecto", esa filía homonoética, significativamente vuelve a aparecer al final de la Respuesta a Abamón, cuando Jámblico se despide de Porfirio. Dice a la letra:

Ruego, entonces, a los dioses, por lo demás al final de los discursos, que nos procuren a ti y a mí la vigilia inmutable de las verdaderas intelecciones, nos instalen la verdad para el eterno siglo y nos den la participación de las más perfectas intelecciones acerca de los dioses, en las cuales también se nos propone el fin más dichoso de los bienes, y la confirmación misma de la amistad armónica en el intelecto de unos con otros. ${ }^{52}$

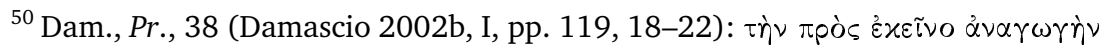

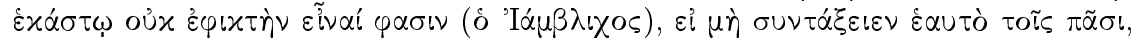

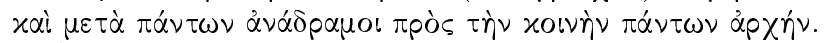

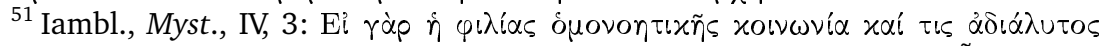

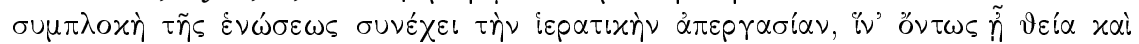

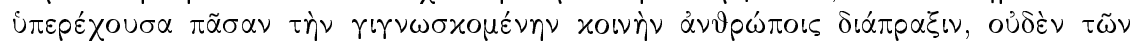

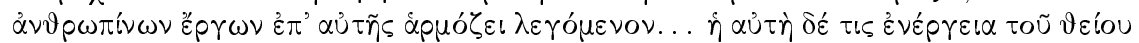

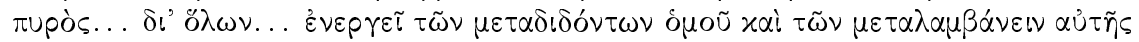

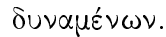

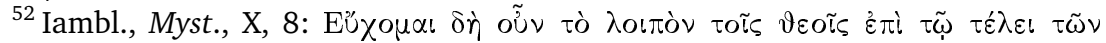

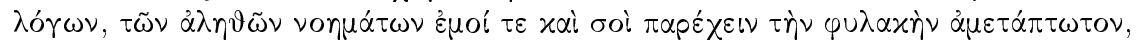

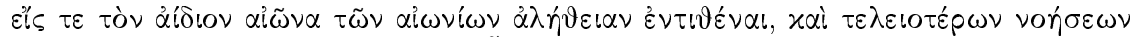

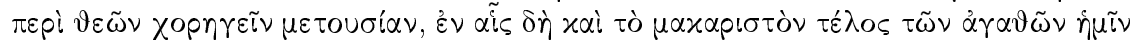

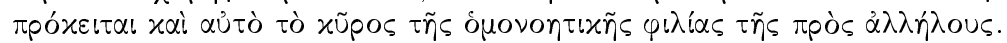

Diánoia, vol. LV, no. 65 (Noviembre 2010). 
En una particular relación con este pasaje, Damascio nos conserva otro texto que parece definitivo en mi interés de señalar la vía de comunión o solidaridad que Jámblico traza rumbo al Uno:

¿Por qué la causa se entrega a sí misma a lo mezclado? Porque se supone que ella, por su capacidad de abarcar todo, es todas las cosas. En efecto, lo simple no es capaz de alojar su potencia, que inefablemente, más allá del uno, reúne todas las cosas. Es imposible, afirma el divino Jámblico, que éstas, de manera individual, participen de los órdenes comunes, a menos que lo hagan junto con el divino coro de los que se elevan de manera intelectualmente armónica. También los atenienses ofrecían plegarias, sólo por su ciudad, a Atenea Guardiana de la ciudad, para que supervisara lo común, no de verdad en privado por cada uno. ${ }^{53}$

Aquí aparece claro que, en el pensamiento de Jámblico, la teúrgia implica también que el ascenso hacia el Uno no puede ser individual, sino que debe ser colectivo; se muestra también la idea del "coro" que se

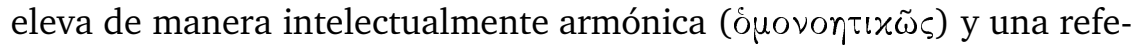
rencia política, la ciudad que reza por el bien común, que va más allá de una simple metáfora.

Es verdad que ese divino coro, ${ }^{54}$ estrictamente hablando, se refiere a los seres superiores y no a seres humanos; sin embargo, no creo que sea casualidad que tanto Proclo como Libanio se refieran a los maestros de filosofía como a un "coro divino" entre los que sin duda está Jámblico. ${ }^{55}$

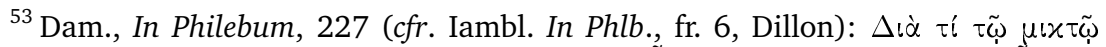

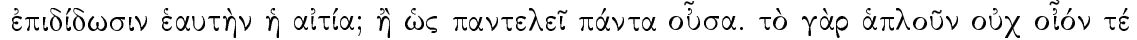

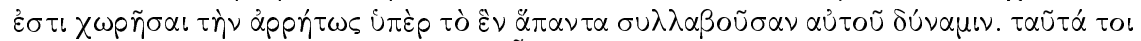

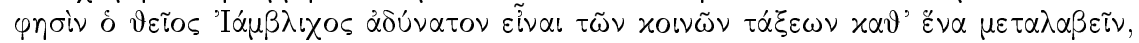

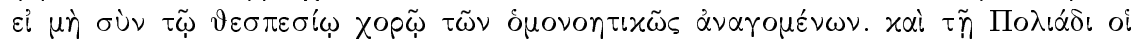

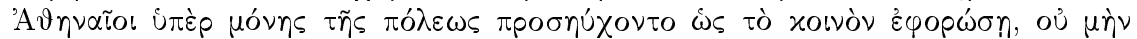

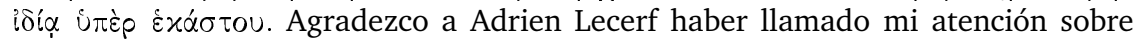
este pasaje; en su correo electrónico del 16 de marzo de 2009 escribía al respecto: "Aquí tiene usted todo: la idea de que el ascenso hacia el Uno debe ser de manera colectiva; la imagen del coro, y la metáfora política enunciada con claridad, lo cual es señal suficiente para mí de que Jámblico pensaba que de hecho la teúrgia tenía un valor político (la teúrgia unifica las ciudades o a la humanidad en las plegarias, una teoría que evidentemente tiene algo que ver con el deseo de Jámblico de tener en cuenta las vidas de la 'gente común'... aun cuando algunas veces la llame 'el rebaño')".

${ }^{54}$ Otra referencia a ese coro aparece en Iambl., In Timaeum, fr. 79 (Dillon).

${ }^{55}$ Procl., Theol. Plat., I, 1 (Proclo 1968, pp. 6-7, Saffrey-Westerink): Toútous òn

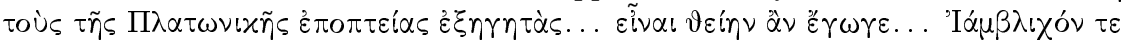

Diánoia, vol. LV, no. 65 (Noviembre 2010). 
En todo caso, Jámblico se concibe como parte de un gremio que también se encuentra ordenado jerárquicamente; afirma, primero, que Porfirio hace bien en dirigirse a los sacerdotes para aclarar sus dudas y que Porfirio puede pensar, o bien, que quien le responde es Anebón, a quien se dirigió la carta, o bien Abamón, maestro de Anebón, o cualquier otro de los sacerdotes. ${ }^{56}$ Abamón responde como miembro de un grupo, diciendo "nosotros" y se refiere a las doctrinas con las que contestará como "las nuestras"; 57 y también, más adelante, AbamónJámblico se refiere al colegio sacerdotal como una entidad que no sólo está unida, sino que se distingue de los demás mortales, cuando dice: "Por tanto, ni nosotros los sacerdotes hemos aprendido de parte de los dioses nada de acuerdo con este argumento, ni tú nos interrogas correctamente como si supiéramos algo más, si en nada nos distinguimos de los demás hombres."58 Así pues, hay un aspecto colegiado de quienes enseñan correctamente los asuntos sobre los que Porfirio inquiere. Me parece, pues, que la teúrgia tiene, no un carácter popular o populista, sino comunitario para quienes la practican. En todo caso, la diferencia a la que apuntan los escasos testimonios entre el misticismo, que ha sido llamado "solitario", de Plotino, ${ }^{59}$ y la vía comunitaria, teúrgica, para unirse al Uno, pueden verse, si atendiendo a este aspecto se leen la Vida de Plotino de Porfirio y la Vida pitagórica de Jámblico, por no mencionar el pasaje de la controvertida Vida de los sofistas de Eunapio (Filóstrato y Eunapio 1968), donde Jámblico aparece junto con sus discípulos tras haber cumplido con los sacrificios de una festividad solar, ${ }^{60}$ mientras que Porfirio nos retrata a un Plotino que no quiere unirse a Amelio para hacer una visita a los templos. ${ }^{61}$ Tal vez, como en otros casos, la diferencia entre Plotino y Jámblico sea sólo aparente, y también para Plotino estar unido al Uno, simultáneamente sea abrazar todo y a todos.

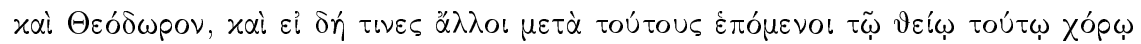

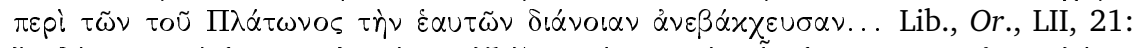

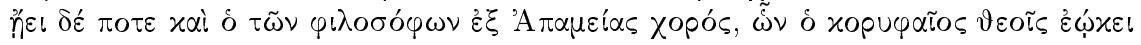

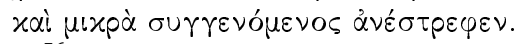

${ }^{56}$ Iambl., Myst., I, 1.

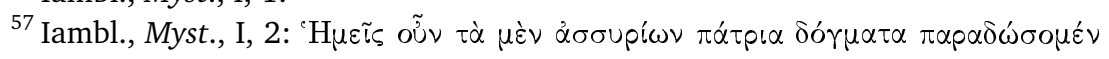

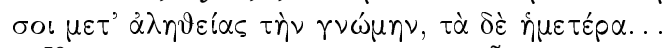

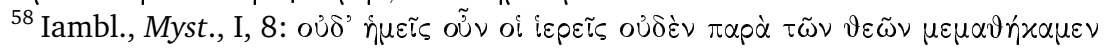

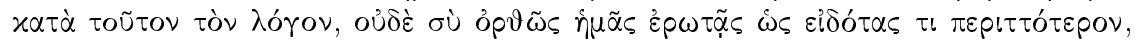

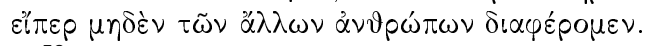

${ }^{59}$ Corrigan 1996.

${ }^{60}$ Eun., VS., 459.

${ }^{61}$ Porph., Plot., 10. 
Termino diciendo que, de alguna manera, esa misma idea, a propósito de un misticismo que implica la unión de la comunidad, me parece, late en una frase no de Jámblico, sino de San Juan, cuando decía: "quien no ama a su hermano, a quien ve, no puede amar a Dios a quien no ve". 62 *

\section{BIBLIOGRAFÍA}

\section{FUENTES}

\section{1. Jámblico}

A) Comentarios

Jámblico 1973 Iamblichi Chalcidensis, In Platonis Dialogos Commentariorum Fragmenta, trad., ed. y comentarios de J.M. Dillon, E.J. Brill, Leiden (Philosophia Antiqua, XXIII).

B) Colección de las Doctrinas Pitagóricas

Dalsgaard 1972 Dalsgaard Larsen, B., 1972, Jamblique de Chalcis: Éxégète et philosophe (Appendice: Testimonia et fragmenta exegeti$\mathrm{ca}$ ), Universitetsforlaget, Aarhus.

Protréptico:

Jámblico 1989 Jamblique, Protreptique, texto establecido y trad. É. Des Places, Les Belles Lettres, París.

C) Acerca del alma

Jámblico 2002 Iamblichus, De Anima, trad. y comentarios de F. Finamore, y J.M. Dillon, Brill, Leiden.

D) Acerca de los misterios egipcios

Jámblico 1996 Jamblique, Les mystères d'Égipte, texto establecido y trad. É. Des Places, Les Belles Lettres, París; 1a. ed.: 1966.

${ }^{62} 1 \mathrm{Jn}, 4,20$.

*Una versión en inglés de este artículo fue presentada en el Seminario "Iamblichos. His Sources and Influences", organizado por el Center for Ancient Philosophy and the Classical Tradition of the University of Novosibirsk, Rusia; el Olympic Centre for Philosophy and Culture, Grecia, y el Irish Institute of Hellenic Studies at Athens, que se llevó a cabo los días 8, 9 y 10 de marzo de 2009, en Atenas, Grecia. Agradezco a los dictaminadores de Diánoia todas y cada una de las sugerencias y correcciones que hicieron a la versión castellana previa de este artículo. Señalo que las versiones del griego y del latín al castellano son mías, dado que uno de los dictaminadores lo considera aconsejable: "los textos de Jámblico son muy difíciles y la traducción propuesta por el autor es fruto de un conocimiento profundo del griego. Por esta razón, creo que el autor debería señalar que la traducción es suya".

Diánoia, vol. LV, no. 65 (Noviembre 2010). 


\section{Otros autores antiguos}

Agustín, Santo, obispo de Hipona, 1981, De civitate Dei Libri XXII, 5a. ed., rec. B. Dombart y A. Kalb, B.G. Teubner, Stuttgart, 2 vols. (Bibliotheca Scriptorum Graecorum et Romanorum Teubneriana)

Biblia de Jerusalén, 1998, Desclée de Brouwer, Bilbao.

Damascio, 2002a, Commentaire du Parménide de Platon, I, texto establecido por L.G. Westerink, trad., introd. y notas de Joseph Combès, Les Belles Lettres, París.

—, $2002 \mathrm{~b}$, Traité des premiers principes, texto establecido por L.G. Westerink; trad. Joseph Combès, Les Belles Lettres, París, 3 vols.

— 1959, Lectures on the Philebus Wrongly Attributed to Olympiodorus, ed. L.G. Westerink, North Holland, Amsterdam.

Eunapio, vid. Filóstrato.

Filóstrato y Eunapio, 1968, The Lives of the Sophists, trad. Wilmer Cave Wright, William Heinemann, Londres (Loeb Classical Library, 134).

Libanio, 1908, Libanius opera, vol. IV, Orationes LIV-LXIV, recensuit Richardus Foerster, Lipsiae, In aedibus B.G. Teubneri (Bibliotheca Scriptorum Graecorum et Romanorum Teubneriana).

Marino de Neápolis, 1999, Proclo o de la felicidad, trad. Jesús María Álvarez Hoz y José Miguel García Ruiz, Iralka, Bilbao.

Numenio de Apamea, 1991, Oráculos caldeos. Fragmentos y testimonios. Con una selección de testimonios de Proclo, Pselo y M. Itálico, trad., introd. y notas de Francisco García Bazán, Gredos, Madrid (Biblioteca Clásica Gredos, 153).

Platón, 1988, Platonis opera, recognovit brevique adnotatione critica inxtruxit Ioannes Burnet, $\mathrm{E}$ typographeo Clarendoniano $=$ Clarendon Press, Oxonii $=$ Oxford (Scriptorum Classicorum Bibliotheca Oxoniensis).

Plotino, 1966-1988, Enneads, trad. A.H. Armstrong, W. William Heinemann/ Harvard University Press, Londres/Cambridge, Mass., 7 vols. (Loeb Classical Library).

Proclo, 1968, Théologie platonicienne I, texto establecido y trad. H.D. Saffrey y L.G. Westerink, Les Belles Lettres, París.

_ 1978, Théologie platonicienne III, texto establecido y trad. H.D. Saffrey y L.G. Westerink, Les Belles Lettres, París.

\section{BIBLIOGRAFÍA GENERAL}

Blumenthal, H.J. y E.G. Clark (comps.), 1993, The Divine Iamblichus. Philosopher and Man of Gods, Bristol Classical Press, Londres.

Clarke, E.C., 2001, Iamblichus' De Mysteriis. A Manifesto of the Miraculous, Ashgate, Burlington.

Corrigan, K., 1996, “'Solitary' Mysticism in Plotinus, Proclus, Gregory of Nyssa, and Pseudo-Dionysius", The Journal of Religion, vol. 76, no. 1, pp. 28-42.

Dillon, J., 1988, "Porphyry and Iamblichus in Proclus' Commentary on the Parmenides", en John Duffy y John Perodotto (comps.), Gonimos. Neoplatonic 
and Byzantine Studies presented to Leendert G. Westerink at 75, Arethusa, Buffalo/Nueva York, pp. 21-48.

Dillon, J., 1978, "The Descent of the Soul in Middle Platonic and Gnostic Theory", en B. Layton (comp.), The Rediscovery of Gnosticism, Proceedings of the International Conference on Gnosticism at Yale New Haven, Connecticut, March 28-31, vol. I: The School of Valentinus, E.J. Brill, Leiden 1980 (= 1978), pp. 357-364.

Dodds, E.R., 1984, The Greeks and the Irrational, University of California Press, Berkeley, Los Ángeles/Londres; 1a. ed.: 1951.

Edwards, M.J., 1997, "Being, Life and Mind", Syllecta Classica, vol. 8, Iamblichus: The Philosopher, ed. Henry J. Blumenthal y John F. Finamore, pp. 191205.

Jonas, H., 2000, La religión gnóstica, trad. Menchu Gutiérrez, Siruela, Madrid. Mazur, Z., 2008, "Unio Intellectualis? A Response to Beierwaltes on Unio Magica”, Dionysius, vol. 26, pp. 193-200.

— 2004, "Unio Magica: Part II: Plotinus, Theurgy, and the Question of Ritual", Dionysius, vol. 22, pp. 29-56.

— 2003, "Unio Magica: Part I: On the Magical Origins of Plotinus' Mysticism", Dionysius, vol. 21, pp. 23-52.

Nasemann, B., 1991, Theurgie und Philosophie in Jamblichs' De Mysteriis, B.G. Teubner, Stuttgart.

O'Meara, Dominic J., 1993, "Aspects of Political Philosophy in Iamblichus", en Blumenthal y Clark 1993, pp. 65-72.

Pearson, B.A., 1992, "Theurgic Tendencies in Gnosticism and Iamblichus's Conception of Theurgy", en R.T. Wallis y J. Bregman, Neoplatonism and Gnosticism, Albany, State University of New York Press, pp. 253-275.

Shaw, G., 1995, Theurgy and the Soul. The Neoplatonism of Iamblichus, The Pennsylvania State University Press, University Park, 1995.

— 1993 , "The Geometry of Grace: A Pythagorean Approach to Theurgy", en Blumenthal y Clark 1993, pp. 116-137.

_ 1988, "Theurgy as Demiurgy: Iamblichus' Solution to the Problem of Embodiment", Dyonisius, vol. 12, 1988, pp. 37-59.

_ 1985, "Theurgy: Rituals of Unification in the Neoplatonism of Iamblichus", Traditio, vol. 41, pp. 1-28.

Sheppard, A., 1982, "Proclus' Attitude to Theurgy", Classical Quarterly, vol. 32, no. 1, pp. 212-214.

Staab, G., 2002, Pythagoras in der Spätantike, Studien zu De Vita Pythagorica des Iamblichos von Chalkis, K.G. Saur, Leipzig.

Stäcker, Th., 1995, Die Stellung der Theurgie in der Lehre Jamblichs, Peter Lang, Fráncfort del Meno (Studien zur klassischen Philologie, 92).

Steel, C.G., 1997, "Iamblichus and the Theological Interpretation of the Parmenides", Syllecta Classica, vol. 8, Iamblichus: The Philosopher, ed. H.J. Blumenthal y J.F. Finamore, pp. 15-30.

—, 1978, The Changing Self. A Study on the Soul in Later Neoplatonism: Iamblichus, Damascius and Priscianus, Paleis der Academiën, Bruselas. 
Zeller, E., 1968, La filosofia dei greci nel suo sviluppo storico. Parte III. La filosofia post-aristotelica, trad. y actualización R. Mondolfo, vol. VI, Giamblico e la scuola di Atene, ed. Giuseppe Martano, La Nuova Italia, Florencia.

Zintzen, C., 1983, "Bemerkungen zum Aufstiegsweg der Seele in Jamblichs De Mysteriis", en Horst-Dieter Blume y Friedhelm Mann (comps.), Platonismus und Christentum. Festschrift für Heinrich Dörrie, Aschendorffsche, Münster (Jahrbuch für Antike und Christentum, Ergänzungsband 10), pp. 312-328.

$\ldots, 1965$, "Die Wertung von Mystik und Magie in der neuplatonischen Philosophie", Rheinisches Museum für Philologie, vol. 108, no. 1, pp. 71-100; también incluido en id. (comp.), Die Philosophie des Neuplatonismus, Wissenschaftliche Buchgesellschaft, Darmstadt, 1977, pp. 391-426.

Recibido el 1 de diciembre de 2008; aceptado el 10 de marzo de 2010. 